\title{
Echocardiographic assessment of artificial heart valves: British Society of Echocardiography position paper
}

\author{
John Chambers, Alan Fraser, Pat Lawford, Petros Nihoyannopoulos, Iain Simpson
}

More than 5000 artificial heart valves are implanted each year in the United Kingdom. About three quarters are mechanical ${ }^{1}$ and about two thirds are implanted in the aortic position.

Echocardiography is universally used to confirm normal function or to detect and quantify dysfunction of the valve. Because of shielding it is more difficult to study artificial valves than native valves and the results are harder to interpret because there is no clearcut distinction between normal and abnormal function: all valves are stenotic compared with normal native valves. In addition artificial valves (table 1) have different orifice characteristics, downstream flow profiles, and patterns of physiological regurgitation: experience gained with one type cannot necessarily be applied to another.

There is no consensus to guide practice, though the Food and Drug Administration in the United States has sent a draft document out for consultation. The aims of this BSE position paper are to describe methods of assessing normally functioning artificial heart valves in terms of forward flow and regurgitation and to discuss the diagnosis of abnormal haemodynamic function. The detection of vegetations and the complications of endocarditis is a separate subject and is not discussed here.

Department of
Cardiology, Guy's
Hospital, London
J Chambers
Department of
Cardiology,
University Hospital of
Wales, Cardiff
A Fraser
Department of
Medical Physics and
Clinical Engineering,
Royal Hallamshire
Hospital, Sheffield
P Lawford
Department of
Cardiology,
Hammersmith
Hospital, London
P Nihoyannopoulos
Department of
Cardiology,
Southampton General
Hospital
I Simpson
Correspondence to:
Dr J Chambers, Department
of Cardiology, Guy's
Hospital, London SE1 9RT.

\section{Normally functioning artificial heart valve}

Artificial valves and ventricular function are usually assessed transthoracically. Additional transoesophageal echocardiography is indicated in a patient with an artificial valve implanted in any position in whom endocarditis is suspected or who has had a cerebral or peripheral embolism and in whom the transthoracic examination is apparently normal. It is essential if dysfunction of a mitral prosthesis is suspected despite an apparently normal or equivocal transthoracic study. It is also useful for the diagnosis of complications, including atrial tamponade or myocardial infarction, in the immediate postoperative period. Where possible a multiplane probe should be available because this provides more comprehensive imaging of the mitral sewing ring than either a single probe or a biplane probe.

\section{TIME OF TESTING}

All valves should be evaluated early after implantation before discharge or at the first postoperative visit to establish a baseline for future comparison. This is necessary because of the wide variation in Doppler values for valves of different design (table 1) and also for valves of the same type and size. Dysfunction is more easily diagnosed by a progressive deterioration than by a single suspicious reading. Post-bypass septal dysfunction, which may take three or more months to resolve, ${ }^{2}$ is less common now than previously and does not interfere significantly with the interpretation of a study.

Mechanical valves do not need further routine assessment unless the possibility of prosthetic malfunction is suggested.

Primary failure of porcine and pericardial valves is usually reported from five years after implantation. ${ }^{34} \mathrm{~A}$ small proportion of the now withdrawn Ionescu-Shiley low-profile valves failed within three years of implantation. Because failure can progress rapidly it must be detected early to allow closer follow up and the planning of elective surgery. Therefore biological valves should generally be assessed every 12 months after the first five years in patients aged over 35 years. If early failure is detected, follow up should be every six months. The failure rate may be accelerated in patients aged less than $35^{56}$ and in those with chronic renal failure. ${ }^{7}$ These patients may need more frequent echocardiographic assessment: this depends on the clinical findings.

Unstented homografts and autografts fail at a lower cumulative frequency and more slowly than xenografts. ${ }^{8}$ They need an annual examination beyond 10 years after implantation or as indicated by the clinical findings.

\section{AORTIC VALVE}

Imaging

The general type of artifical valve should first be established: unstented biological, stented biological, tilting disc, bi-leaflet mechanical, or caged ball (fig 1 and table 1). The appearance and pattern of motion of the cusp or occluder should be noted. The cusps of a biological valve are often seen best in the apical long axis view when the shielding from the ultrasound beam caused by the sewing ring and stents is minimised. The cusps should be thin and should move through an arc of about $90^{\circ}$. The thickness of the cuspal echoes varies with gain and pulse length: the reported mean (SD) is $0.9(0.1) \mathrm{mm} .^{9}$ The disc of a tilting disc valve and the leaflets of a bi-leaflet prosthesis should open quickly, in about $20 \mathrm{~ms}^{1011}$ These valves usually show low frequency vibration of the leaflets on $\mathbf{M}$ mode echocardiography. The ball echo of a caged ball valve 
Table 1 Types and models of artificial heart valves used clinically (1978-1993)

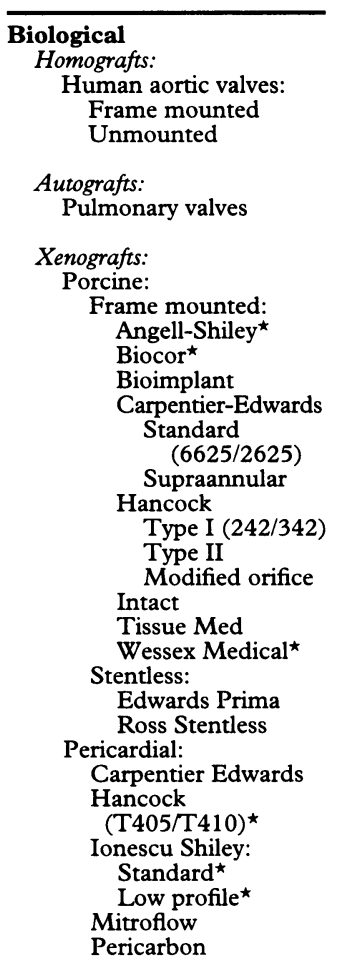

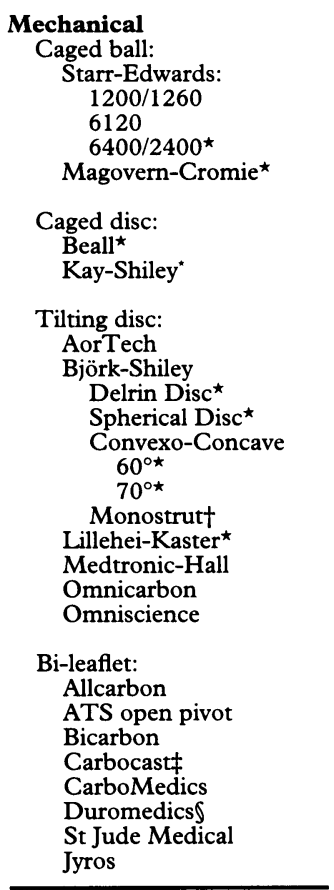

*Withdrawn from sale.

†Now marketed by Sorin as Monostrut.

$\ddagger$ Replaced by Allcarbon in UK

IWithdrawn 1988, modified version undergoing clinical trials. recorded on $\mathrm{M}$ mode makes contact with the echo from the tip of the cage and there is often an irregular bouncing motion of the ball during systole. Rocking of the valve is a sign of dehiscence and is seldom seen in a normal valve.

\section{Colour flow mapping}

Colour mapping is not usually helpful for assessing forward flow in aortic valves, but is necessary for detecting, localising, and estimating the severity of regurgitation. All windows should be used but the site of the jets is usually most easily seen in the parasternal short axis view.

Normal xenografts rarely leak unless they have been implanted for more than 48 months. ${ }^{12}{ }^{13}$ None the less, there are reports of minor regurgitation in valves implanted for less than 2 years. ${ }^{14}$ Similarly, normal homografts rarely leak until early primary failure develops. In contrast, minor regurgitation is the rule in autografts even immediately after implantation. Mechanical valves commonly have two phases of normal regurgitation-a closing volume as the occluder shuts and true leakage around the closed occluder (fig 2). Single tilting disc valves have two tails of regurgitation, one from each side of the disc. These are usually larger in Medtronic-Hall than Björk-Shiley valves. In Starr-Edwards valves the jet is smaller and the pattern of regurgitation is variable. There may be one or more individual jets or there may be diffuse leakage around the ball. Little regurgitation is seen for the St Jude bi-leaflet valve. The CarboMedics prosthesis has a different type of regurgitation. It consists of washing jets on either side of each pivotal point. These last throughout diastole and their eccentric position makes them particularly easy to mistake for paraprosthetic leakage. ${ }^{15} \mathrm{Up}$ to four individual jets can usually be distinguished.

Transoesophageal examination shows normal transprosthetic regurgitation in almost all mechanical valves. Both closing volume and true leakage can be detected. Minor regurgitation is also common in newly implanted aortic prostheses. ${ }^{1416}$ The identification and measurement of transprosthetic and paraprosthetic regurgitation are discussed below.

\section{Spectral Doppler}

Continuous wave recordings should always be made from the apex and either the right intercostal space or suprasternal notch. If signals from these positions are not adequate the subcostal approach should also be used. In general a stand-alone probe is more sensitive than a steerable continuous wave probe.

Pulsed Doppler recordings should be made in the apical five chamber or apical long axis view and colour flow mapping may be useful for positioning the cursor in line with blood flow. The sample volume should be at minimum length and placed just below the start of flow acceleration, usually at $0.5 \mathrm{~cm}$ to $1 \mathrm{~cm}$ below the level of the annulus.

Velocity-Peak velocity should be averaged over $3-5$ consecutive beats if the patient is in sinus rhythm or over 5-10 beats if in atrial fibrillation. It should be measured at the top of the dense part only of waveforms with a well defined peak. Homografts have peak velocities similar to those of a normal native valve. ${ }^{18}$ Porcine xenografts give substantially raised values with velocities of $2-4 \mathrm{~m} / \mathrm{s}^{13}{ }^{17}$ Even higher values are seen in caged ball valves, with peak velocities of $3-4 \mathrm{~m} / \mathrm{s} .{ }^{18-20}$ Single tilting disc valves commonly give velocities of $3 \mathrm{~m} / \mathrm{s}^{21}{ }^{22} \mathrm{Bi}$-leaflet mechanical valves are less obstructive, with values around $2 \cdot 0 \mathrm{~m} / \mathrm{s}$ except for the $19 \mathrm{~mm}$ annulus where the peak velocity for both CarboMedics and St Jude Medical unmodified valves can reach $4 \cdot 0 \mathrm{~m} / \mathrm{s} .{ }^{1523}$ Two major cautions apply to the interpretation of peak velocities of valves of all types. Firstly, peak velocity may be unrepresentative of valve function. It is common to find high instantaneous peak velocities in early systole particularly if cardiac output is high. These may be caused partly by non-uniform flow profiles. These velocities are not, however, sustained as in aortic stenosis and if used alone would lead to overdiagnosis of obstruction. Mean velocity, therefore, should also be measured. It can be calculated by planimetry of the waveform with online software and is usually between half and two thirds of the peak velocity. Secondly, velocities are highly dependent on cardiac output and cannot be interpreted in isolation. A peak instantaneous velocity of 3.0 $\mathrm{m} / \mathrm{s}$ could be found in a normal valve at high flows (for example, in the presence of anaemia) or in a significantly obstructed valve at low flows. Thus if the initial examination shows impaired left ventricular systolic function or a surprisingly high peak velocity, flow correction must be performed by either the continuity equation or the velocity ratio (see below).

\section{Pressure drop}

Estimation of pressure drop (gradient) $(\Delta \mathrm{P})$ from the transaortic velocity $\left(\mathrm{v}_{2}\right)$ using the modified Bernoulli equation should not be used routinely.

$$
\Delta \mathrm{P}=4 \mathrm{v}_{2}{ }^{2}
$$

This overestimates the pressure drop that would be found at cardiac catheterisation and may lead to overdiagnosis of obstruction. ${ }^{2425}$ The overestimation occurs for two reasons. First, Doppler derived velocities reflect the true instantaneous pressure difference between left ventricle and the aorta immediately above the valve. At pullback with a cardiac catheter the difference between nonsimultaneous peak pressures is measured between the left ventricle and a point downstream from the valve. The pullback gradient is always less than the peak instantaneous gradient. Secondly, the modified equation neglects subaortic velocity $\left(v_{1}\right)$, which is proportionately more important in normal artificial valves than in aortic stenosis. If a guide to pressure drop is required it should be calculated from the formula:

$$
\Delta \mathrm{P}=4\left(\mathrm{v}_{2}{ }^{2}-\mathrm{v}_{1}{ }^{2}\right)
$$

For a valve where the subaortic velocity is $1 \cdot 0$ 


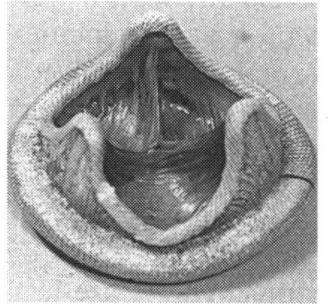

Xenograft (Standard Carpentier-Edwards)

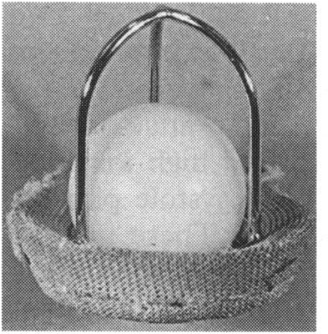

Caged ball (StarrEdwards, model 260)

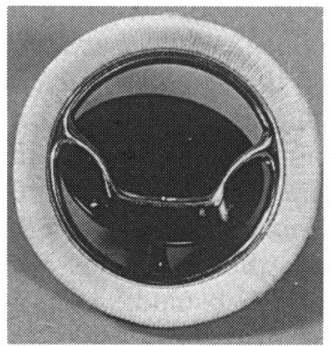

Single tilting disc (BjörkShiley, Monostrut)

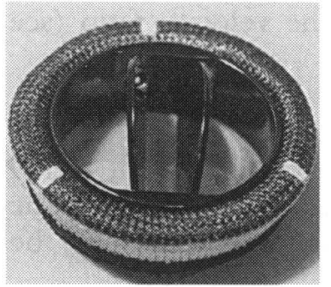

Bi-leaflet mechanical (CarboMedics)

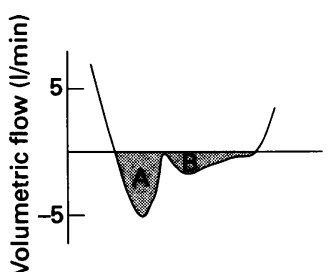

Figure 2 Physiological regurgitation through a mechanical heart valve prosthesis. A, closing volume; $B$, true leakage. $\mathrm{m} / \mathrm{s}$ and the transaortic velocity $2.0 \mathrm{~m} / \mathrm{s}$ the estimated pressure drop is $12 \mathrm{~mm} \mathrm{Hg}$ with equation 2 compared with $16 \mathrm{~mm} \mathrm{Hg}$ with equation 1 .

Effective orifice area by the continuity equation This equation should be used if the left ventricle is significantly impaired or if the peak transaortic velocity is high (say $>3.0 \mathrm{~m} / \mathrm{s}$ ) and it is not certain whether this is because of relative obstruction or high flow.

$$
\mathrm{EOA}=\mathrm{CSA} \times \mathrm{VTI}_{1} / \mathrm{VTI}_{2}
$$

Where EOA is the effective orifice area, $\mathrm{VTI}_{1}$ is the subaortic velocity integral, and $\mathrm{VTI}_{2}$ is the transaortic velocity integral.

The use of the product of CSA and $\mathrm{VTI}_{1}$ has been validated for artificial heart valves. ${ }^{26}$ The continuity equation can be simplified by assuming similar waveform shape above and below the valve:

$$
\mathrm{EOA}=\mathrm{CSA} \times \mathrm{v}_{1} / \mathrm{v}_{2}
$$

where $v_{1}$ is the subaortic peak velocity and $v_{2}$ is the aortic velocity. This form of the equation is simpler to apply and is in general use but tends to underestimate at orifice areas above 1.0 $\mathrm{cm}^{2} .{ }^{27} \mathrm{CSA}$ is calculated from the left ventricular outflow tract diameter (d) assuming a circular cross section:

$$
\operatorname{CSA}=\pi \cdot d^{2} / 4
$$

The diameter of the left ventricular outflow tract should be averaged from three parasternal long axis frames frozen in early systole. Care must be taken to open out this region until the dimension looks maximal. The measurement should be made from the leading edge of the left septal echo to the leading edge of the anterior mitral leaflet echo. ${ }^{28}$ The measurement should not be made if there is severe left ventricular hypertrophy or bowing of the anterior mitral leaflet. It should be performed with a coexistent mitral prosthesis only if the blooming from the sewing ring of the mitral valve is trivial.

The continuity equation is limited by its wide confidence intervals (CI). For normally functioning bi-leaflet valves the difference between measured and calculated orifice area has a $95 \% \mathrm{CI}$ of around -0.5 to $+0.5 \mathrm{~cm}^{2} .^{29}$ with errors arising mainly in the measurement of subaortic diameter and subaortic velocity. In practice, the effective area has to be regarded as a semiquantitative guide rather than as a precise measure of function.

\section{Velocity ratio}

The ratio of peak subaortic to peak transaortic velocity gives an approximate guide to orifice behaviour. It is equivalent to a performance index (the ratio of effective orifice area to total valve area). It is useful for serial measurements in the same individual where the diameter of the left ventricular outflow tract can be assumed to be constant. It can also be applied in an isolated study if the diameter of the left ventricular outflow tract is difficult to measure. Its accuracy for the detection of dysfunction in this situation will be low. ${ }^{23}$

\section{MITRAL VALVE}

\section{Imaging}

The type of valve is more easily identified in the mitral position than in the aortic position because the stents, occluder, and cage protrude into the left ventricular cavity where they are imaged easily.

The cuspal echoes from porcine xenografts should be thin. The mean (SD) thickness in one study was $1.2(0.1) \mathrm{mm} .{ }^{9}$ Each of the three cusps may open at different rates and to different degrees and at a low cardiac output it is not unusual for one cusp to stay closed throughout diastole. A tilting disc valve should open and close quickly giving a sharp initial $\mathrm{E}$ point with only a small early diastolic hump on the $M$ mode recording. The ball of a caged ball prosthesis may appear to move into the left atrium in systole. This occurs as a result of reverberation artefact and, if the ball is Silastic, of the slow conduction of sound through the ball. An $M$ mode scan through the longitudinal axis of the cage shows that the ball makes contact with the tip of the cage during diastole. The leaflets of a bi-leaflet mechanical prosthesis can be imaged most easily from the apical approach and should open and close quickly in unison. It is common to see mobile strands up to $15 \mathrm{~mm}$ in length attached to the pivot or occasionally to the sewing ring of a St Jude prosthesis on transoesophageal echocardiography. ${ }^{30} 31$ These seem to have no pathological significance.

Rocking of a mitral valve should be noted but it may be normal. It can occur when the valve is sewn onto a partially or fully retained posterior leaflet. Abnormal rocking is shown by a gap opening up at the point of maximum amplitude of valve motion during systole and by its association with a regurgitant jet. A piston-like motion may be seen in normal valves and is generally caused by the presence of a diaphragm of tissue around the prosthesis.

\section{Colour flow mapping}

In a normal biological prosthesis or the $\mathrm{St}$ Jude Medical or CarboMedics bi-leaflet mechanical prostheses the colour map fills the whole width of the orifice in all views. For a tilting disc valve, there is usually a major and minor tail and in the Duromedics bi-leaflet valve there are three jets. A caged ball valve has two jets curving around the ball that meet centrally above the cage.

To detect regurgitation the left atrium must be imaged from all standard views and also from any off-axis view that reduces shielding by the occluder and sewing ring. Normal transvalvar mitral regurgitation is rarely seen transthoracically except when the left atrium is large. Evanescent puffs of regurgitation may be found in designs, such as the MedtronicHall tilting disc valve, in which the closing volumes are relatively large.

On transoesophageal examination normal transprosthetic regurgitation can be found in almost all mechanical valves. Minor regurgitation was also seen by Mohr-Kahaly in most mitral bioprostheses even when newly implanted $^{14}$ though others reported a lower 
incidence $(25 \%){ }^{16}$ These jets are usually short and narrow. ${ }^{14}{ }^{32-35}$ They are less than $2 \cdot 5 \mathrm{~cm}$ long in caged ball valves; about $3-4 \mathrm{~cm}$ long in Björk-Shiley, St Jude, and CarboMedics valves; and up to $5 \mathrm{~cm}$ long in Medtronic Hall valves. Most jets are about $1 \mathrm{~cm}$ wide. Their site and number depend on the valve design. In the Björk-Shiley prosthesis there are two jets, and in the Medtronic-Hall there are two peripheral jets and one central jet. ${ }^{34}$ The St Jude has two or three, the CarboMedics valve has two jets from each pivotal point, and the Starr-Edwards has one central jet early in the cycle. ${ }^{36} 37$ These jets are often visually impressive and must not be mistaken for significant
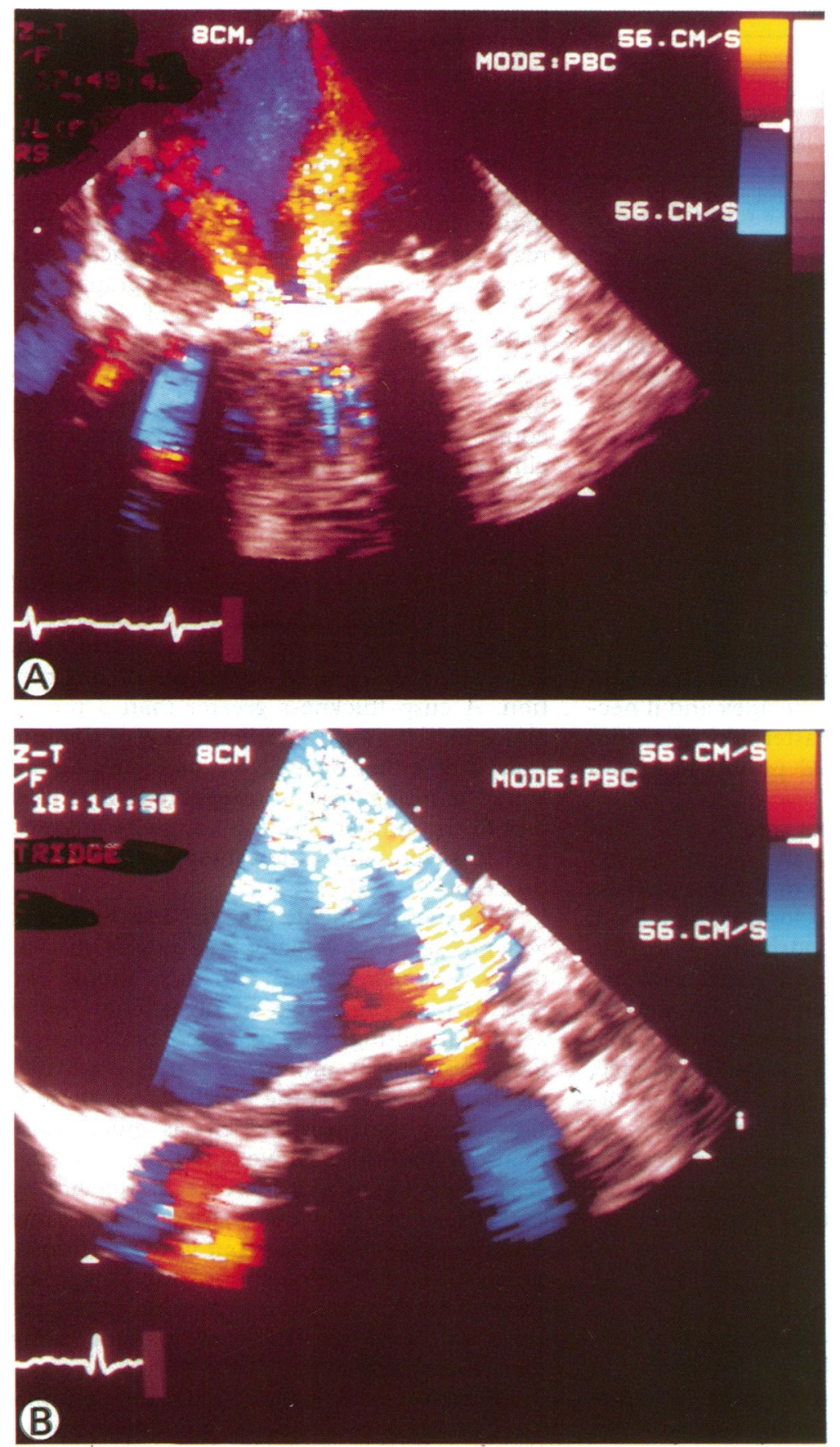

Figure 3 Normal and pathological mitral regurgitation on transoesophageal echocardiography. (A) A Björk-Shiley prosthesis with two jets of low momentum normal transprosthetic regurgitation. (B) $A$ broader jet in a paraprosthetic position. paraprosthetic regurgitation. Because of their lower momentum they are usually more homogeneous in colour than paraprosthetic jets (fig 3).

\section{Spectral Doppler}

Continuous wave recordings of transmitral flow should be made from the apex. They may also be obtained if necessary from the parasternal position.

Velocity-Peak velocity should be averaged over 3-5 consecutive beats if the patient is in sinus rhythm or over 5-10 beats in atrial fibrillation. Mean velocity should also be calculated by planimetry of the waveform using online software.

Pressure drop-The mean pressure drop does not need to be calculated routinely. If an approximation to catheter derived information is required, the mean pressure drop can be obtained using online software by planimetry of the waveforms.

Pressure half time-Pressure half time should be averaged over five beats with cycle lengths equivalent to instantaneous heart rates of $60-90$ beats per min. The online software can be used if the waveform has a linear deceleration, otherwise the measurement should be made manually. ${ }^{38}$ Pressure half time is determined by several factors in addition to orifice area. These include atrial and ventricular compliance, stroke volume, and the square root of the transmitral pressure drop at the start of diastole. ${ }^{39}$ In normal mitral valves pressure half time is mainly determined by non-prosthetic factors and is not closely related to annulus diameter or orifice area. However, bi-leaflet mechanical valves tend to have pressure half times approaching those of a normal native valve whereas the more obstructive valves such as the porcine biological valve or the caged ball valves frequently have times $>100 \mathrm{~ms}$ (table 2). Pressure half times of $<200 \mathrm{~ms}$ are usually normal. The Hatle formula for orifice area should not be applied to normally functioning artificial heart valves. If an estimate of orifice area is required for research purposes the continuity equation can be used. Stroke volume calculated either at the aortic or pulmonary valve should be divided by the mean area under the transmitral signal measured by planimetry.

Pulmonary artery systolic pressure-This should be estimated, where possible, in every case. Colour mapping helps with the orientation of the continuous wave beam and if necessary contrast enhancement should be used. The pressure difference between the right ventricle and right atrium should be estimated from the highest peak velocity obtained using the modified Bernoulli equation. To this should be added an estimate of right atrial pressure made from the behaviour of the inferior vena cava imaged from the subcostal position (table 3)..$^{40}$

\section{TRICUSPID VALVE}

Imaging and colour flow mapping

The appearance and movement of the valve are broadly the same as for the mitral valve, but it is often hard to image a tricuspid valve 
Table 2 Guideline thresholds for abnormal mitral pressure half time (upper 95\% CI of normal)

\begin{tabular}{lllc}
\hline $\begin{array}{l}\text { Valve } \\
\text { design }\end{array}$ & $\begin{array}{l}\text { Study } \\
\text { (reference) }\end{array}$ & $n$ & $\begin{array}{l}\text { Threshold pressure } \\
\text { half rime (ms) }\end{array}$ \\
\hline Native & 38 & 20 & 55 \\
& 42 & 15 & 65 \\
St Jude & 55 & 13 & 94 \\
& 56 & 27 & 131 \\
CarboMedics & 57 & 75 & 117 \\
Björk-Shiley & 58 & 56 & 149 \\
& 59 & 31 & 112 \\
& 42 & 29 & 110 \\
Medtronic-Hall & 20 & 46 & 139 \\
Ionescu-Shiley & 59 & 13 & 103 \\
Carpentier- & 13 & 13 & 139 \\
Edwards & 61 & 28 & 135 \\
& 58 & 78 & 171 \\
Starr-Edwards & 56 & 35 & 142 \\
& 58 & 30 & 206 \\
& 56 & 31 & 170 \\
& 20 & 118 & 147
\end{tabular}

Table 3 Estimation of right atrial pressure from the inferior vena cava

\begin{tabular}{lll}
\hline $\begin{array}{l}\text { IVC dimension } \\
(\mathrm{cm})\end{array}$ & $\begin{array}{l}\text { Contraction in inspiration } \\
(\%)\end{array}$ & $\begin{array}{l}R A \text { pressure } \\
(\mathrm{mm} \mathrm{Hg})\end{array}$ \\
\hline$<2 \cdot 0$ & $>50$ & $5-10$ \\
$>2 \cdot 0$ & $25-50$ & 15 \\
$>2.0$ & $<25$ & 20
\end{tabular}

This is an approximate guide to right atrial pressures based on published research. ${ }^{0}$ Further validation is required. RA, right published research.$^{40}$ Further
atrial; IVC, inferior vena cava.

Table 4 Normal ranges (mean (SD)) for effective aortic area based on the continuity equation.

\begin{tabular}{|c|c|c|}
\hline $\begin{array}{l}\text { Valve type } \\
\text { and } \\
\text { annulus } \\
\text { diameter } \\
(\mathrm{mm})\end{array}$ & $\begin{array}{l}\text { Effective } \\
\text { area } \\
\left(\mathrm{cm}^{2}\right)\end{array}$ & $n$ \\
\hline $\begin{array}{c}\text { St Jude }{ }_{21}^{23} \\
23 \\
25 \\
27 \\
29\end{array}$ & $\begin{array}{l}1 \cdot 3(0 \cdot 2) \\
1 \cdot 3(0 \cdot 3 \\
1 \cdot 8(0 \cdot 4) \\
2 \cdot 4(0 \cdot 6) \\
2 \cdot 7(0 \cdot 3)\end{array}$ & $\begin{array}{r}14 \\
16 \\
14 \\
6 \\
5\end{array}$ \\
\hline $\begin{array}{c}\text { CarboMed } \\
21 \\
23 \\
25 \\
27 \\
29\end{array}$ & $\begin{array}{l}\mathrm{cs}^{48} \\
1 \cdot 6(0 \cdot 3) \\
1 \cdot 7(0 \cdot 3) \\
2 \cdot 0(0 \cdot 4) \\
2 \cdot 4(0 \cdot 4) \\
2 \cdot 6(0 \cdot 3)\end{array}$ & $\begin{array}{r}13 \\
23 \\
27 \\
12 \\
4\end{array}$ \\
\hline $\begin{array}{c}\text { Medtronic } \\
21 \\
23 \\
25 \\
27\end{array}$ & $\begin{array}{c}\text { Intact }^{62} \\
1 \cdot 0(0 \cdot 1) \\
1 \cdot 2(0 \cdot 1) \\
1 \cdot 4(0 \cdot 2) \\
1 \cdot 6(0 \cdot 2)\end{array}$ & $\begin{array}{r}6 \\
8 \\
11 \\
3\end{array}$ \\
\hline $\begin{array}{c}\text { Carpentier } \\
21 \\
23 \\
25 \\
27 \\
29\end{array}$ & $\begin{array}{c}\text { Edwards }^{58} \\
1 \cdot 2(0 \cdot 2) \\
1 \cdot 1(0 \cdot 2) \\
1 \cdot 2(0 \cdot 3) \\
1 \cdot 3(0 \cdot 3) \\
1 \cdot 4(0 \cdot 1)\end{array}$ & $\begin{array}{r}7 \\
23 \\
30 \\
13 \\
3\end{array}$ \\
\hline $\begin{array}{c}\text { Björk Shile } \\
21 \\
23 \\
25 \\
27\end{array}$ & $\begin{array}{l}y^{58} \\
1 \cdot 1(0 \cdot 3) \\
1 \cdot 3(0 \cdot 3) \\
1 \cdot 4(0 \cdot 4) \\
1 \cdot 6(0 \cdot 3)\end{array}$ & $\begin{array}{r}6 \\
16 \\
22 \\
12\end{array}$ \\
\hline $\begin{array}{c}\text { Starr-Edw } \\
21 \\
23 \\
24 \\
26 \\
27\end{array}$ & $\begin{array}{c}\operatorname{rds}^{20} \\
1 \cdot 3(0 \cdot 2) \\
1 \cdot 1(0 \cdot 2) \\
1 \cdot 1(0 \cdot 3 \\
1 \cdot 5(0 \cdot 3)\end{array}$ & $\begin{array}{r}2 \\
10 \\
6 \\
24\end{array}$ \\
\hline $\begin{array}{c}\text { Homograf } \\
21 \\
22 \\
24 \\
26 \\
27\end{array}$ & $\begin{array}{l}2 \cdot 1(1 \cdot 3) \\
2 \cdot 0(0 \cdot 6) \\
1 \cdot 6(0 \cdot 6) \\
2 \cdot 4(0 \cdot 7 \\
2 \cdot 6(1 \cdot 0)\end{array}$ & $\begin{array}{l}3 \\
6 \\
3\end{array}$ \\
\hline
\end{tabular}

$\mathrm{n}=$ number of valves studied. and the patient may need to be positioned further on the left than usual. The width of the colour flow profile gives a guide to valve function.

The following indirect signs of valve function should be assessed: the size of the right atrium, the size and behaviour of the right ventricle, and the effect of respiration on the size of the inferior vena cava.

\section{Spectral Doppler}

Continuous wave recordings of transtricuspid flow should be made from the apex and if necessary from the parasternal position. Sometimes a clearer signal is obtained with pulsed Doppler.

Transtricuspid velocities are lower than transmitral velocities and the peak velocity should usually be below $1.5 \mathrm{~m} / \mathrm{s}$. Most workers quote pressure half times longer than for a similar valve in the mitral position. ${ }^{41} 42$ In fact, pressure half time on the right varies substantially more with respiration than on the left and may be misleading in a normal tricuspid valve. There are few data to guide practice, but there is no reason to expect the Hatle formula to be valid in normal tricuspid valves.

Flow in the hepatic vein and superior vena cava should be measured if high right-sided pressures or tricuspid valve dysfunction are suspected (see below).

\section{PULMONARY VALVE/CONDUIT}

The pulmonary valve should be imaged from the far left lateral position, if necessary in forced expiration, and also from the subcostal approach. Continuous wave recordings should be made from these same positions. Peak instantaneous velocities of around $2 \cdot 0$ $\mathrm{m} / \mathrm{s}$ are usual in pulmonary prostheses.
Indirect signs of the function of a rightsided valve should be assessed, in particular the variation in the diameter of the inferior vena cava with respiration.

\section{Diagnosis of abnormality}

It is not possible to define reliable normal ranges for artificial valve function. There is overlap between the measurements obtained with different designs, between different annulus diameters of the same design, and occasionally between normal and abnormal valves. Importantly, transvalvar velocities depend on cardiac output. Figures derived from Doppler recordings must be balanced with information obtained on imaging and colour flow mapping and also from the clinical examination. Though Doppler echocardiography may produce precise results for an individual valve, the interpretation of these results is open to judgement. The goal of the initial assessment is to classify the valve as definitely normal, definitely abnormal, or equivocal. The next step is to refine the assessment of dysfunction as mild, moderate, or severe. These are broad categories for which the qualitative information obtained from imaging may be as useful as the numerical data obtained from Doppler echocardiography.

Because of the variability of behaviour between valves, dysfunction may often be suggested more easily by a change in results than by a single reading. When the results are equivocal the studies should be repeated after a clinically appropriate interval.

\section{AORTIC VALVE}

\section{Obstruction}

In xenografts both true thickening and a partial tear can cause thickening of the cuspal echo. Generalised thickening and reduced motion, however, are strongly suggestive of obstruction. A cusp thickness greater than $3 \mathrm{~mm}$ is abnormal ${ }^{434}$ and predicts severe failure caused by either obstruction or regurgitation. When a tilting disc is obstructed the initial part of the systolic disc echo appears rounded and in severe cases there may be no systolic disc echo. ${ }^{45}$

Velocities are highly flow dependent, but in general, a peak velocity above $4.0 \mathrm{~m} / \mathrm{s}$ or mean velocity above $3.0 \mathrm{~m} / \mathrm{s}$ should be regarded as suggestive of obstruction for a xenograft, tilting disc, or caged ball valve or for a small $(19 \mathrm{~mm}$ or $21 \mathrm{~mm}$ ) bi-leaflet mechanical valve. If the acceleration phase is slow (or if the mean velocity is much more than one half the peak velocity) this also suggests obstruction. An increase in velocity by say $50 \%$ from previous values in the same patient is also suspicious; but in these circumstances flow correction should also be applied either with the continuity equation or, if previous data exists for the same patient, using the velocity ratio.

Effective area calculated from the continuity equation may be a better guide to the presence of obstruction; but the method is not precise. An area of $1.0 \mathrm{~cm}^{2}$ has been suggested as a threshold for abnormality. ${ }^{46}$ Orifice areas 
between $0.75 \mathrm{~cm}^{2}$ and $1.0 \mathrm{~cm}^{2}$ are commonly found in patients with caged ball valves, porcine bioprostheses, or small tilting disc or bi-leaflet mechanical valves. Table 4 shows the published normal values for effective area. In practice, effective orifice areas of less than $1.0 \mathrm{~cm}^{2}$ should excite suspicion but in a patient without symptoms they may sometimes be normal. If doubt remains the measurement should be repeated after a clinically appropriate interval.

A velocity ratio of $\leqslant 0.2$ is highly suggestive of obstruction and a ratio of $>0.3$ suggests normal function. Values between these figures are equivocal. ${ }^{23} 47$

\section{Regurgitation}

Pathological regurgitation may be either paraprosthetic or transprosthetic. Transprosthetic regurgitation is most common in biological valves. Tears in bioprostheses tend to start at the free edge of a cusp 2 to $3 \mathrm{~mm}$ from the commissural attachment. Endocarditis may lead to tearing of the cusp or perforations in the leaflet tissue. ${ }^{48}$ These degenerative changes may be accompanied by abnormalities of cusp motion on echocardiography. A cusp is described as flail if it moves through an arc of $180^{\circ}$; this abnormality is associated with tears at the margin of the cusp. ${ }^{49} \mathrm{~A}$ partially flail cusp occurs when only a limited portion of a cusp is torn. Cusp prolapse produces movement behind the plane of the sewing ring and this is seen when there are longitudinal tears at the ring or perforations of the cusp. ${ }^{49}$

Transprosthetic regurgitation in xenografts is rare on transthoracic examination within 4 years of implantation and suggests early primary failure. ${ }^{13}$ Trivial regurgitation is, however, commonly seen on transoesophageal examination. ${ }^{14}$ Unstented homografts tend to thicken like native valves and though mild regurgitation may be a sign of early primary

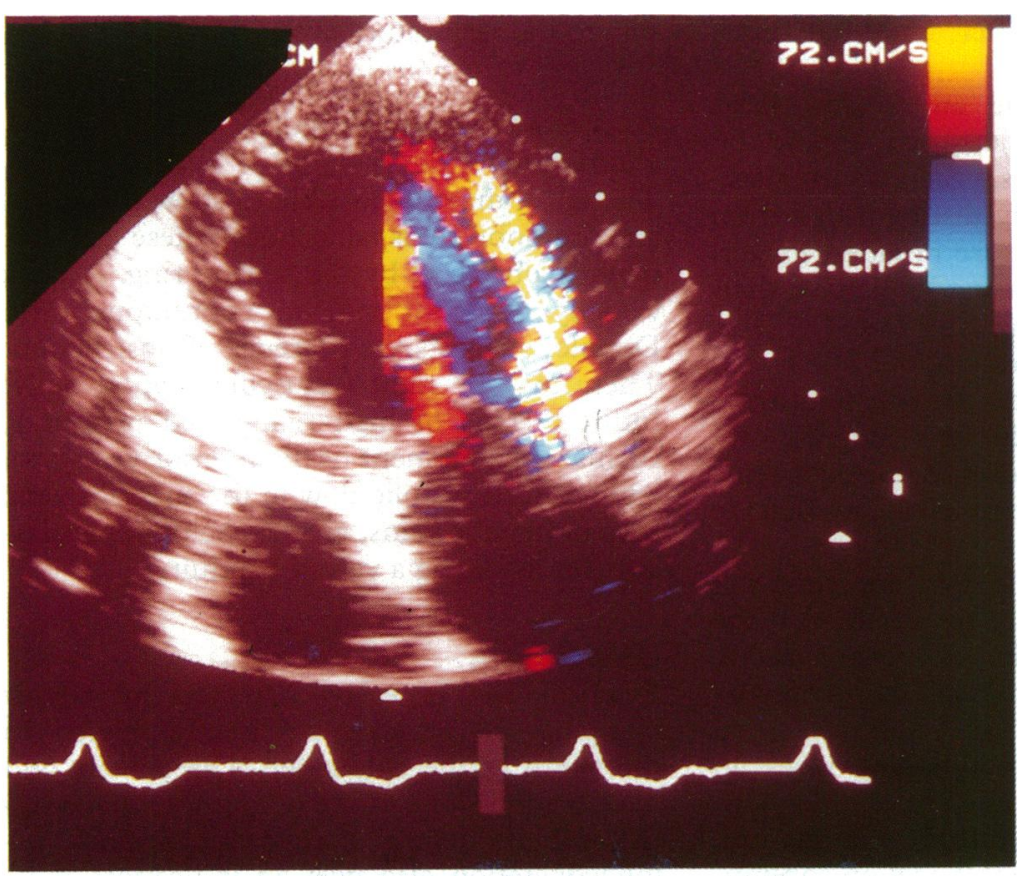

Figure 4 Paraprosthetic aortic regurgitation in a patient with endocarditis. failure, overt failure usually develops slowly. With autografts a small central leak is common immediately after surgery.

Abnormal transprosthetic regurgitation also occurs through mechanical valves when there is ball variance or when thrombus, vegetation, or pannus prevent complete closure of the occluder. Such regurgitation may be distinguishable from normal by greater jet size, but there is no clear division between normal and abnormal.

Colour flow mapping shows paraprosthetic regurgitation as a turbulent jet with its base outside the sewing ring and often associated with a stream of colour around the outer edge of the sewing ring (fig 4). The position of the dehiscence is often best shown in a parasternal short axis view. The extent of the colour map around the sewing ring gives an approximate measure of the severity of regurgitation but tends to underestimate it. Rocking of an aortic prosthesis almost never occurs in the absence of a dehiscence and suggests that around $40 \%$ of the sewing ring is affected. ${ }^{50}$ The width of the jet on colour flow mapping may not be as useful a measure of severity as in native regurgitation because the paraprosthetic jet is often eccentric. Because it passes obliquely across the left ventricular outflow tract it may be difficult to compare with the left ventricular outflow tract height as a standard. The shape of the continuous wave signal, the degree of diastolic flow reversal at the arch, and the state of the left ventricle can be used to assess the severity of prosthetic and native aortic regurgitation.

\section{MITRAL VALVE}

\section{Obstruction}

Signs strongly suggesting obstruction are thickening of the cusps of a bioprosthesis beyond $3 \mathrm{~mm}$ with an associated reduction in mobility. For a mechanical valve, obstruction is suggested by reduction of disc motion or ball excursion, though these may also occur if cardiac output is low. The ball of a caged ball valve may fail to contact the tip of the cage if thrombus is present. Occasionally, failure to open may be intermittent.

The colour flow map is useful despite its limited lateral resolution. Obstruction of the valve can narrow the map at the level of the orifice. $^{4751}$ The map tends to diverge quickly downstream from the orifice so that width must be analysed extremely carefully. An eccentric left ventricular inflow map is a normal finding in single tilting disc valves but suggests obstruction in valves, such as the Carpentier-Edwards porcine bioprosthesis, that normally have central flow.

Pressure half time is closely related to nonprosthetic factors in normal mitral prostheses, so small changes in pressure half time are unlikely to reflect changes in orifice area. Prosthetic obstruction, however, considerably prolongs the pressure half time and this may be a useful corroborative sign, especially when image quality is poor. A pressure half time of longer than $200 \mathrm{~ms}$ is unusual in a normal valve particularly if the peak velocity is above $2.5 \mathrm{~m} / \mathrm{s}$. 
Associated signs of obstruction are a small left ventricle that is slow to fill, paradoxical motion of the septum, and a high estimated pulmonary artery systolic pressure. Because these may also be signs of residual right-sided abnormalities they must always be interpreted in the clinical context.

\section{Regurgitation}

Because shielding is rarely severe in biological valves transprosthetic regurgitation can usually be detected on transthoracic colour mapping. There may also be associated abnormalities of cuspal motion: flail cusp, partial flail cusp, or cusp prolapse. The size of the jet may, however, be significantly underestimated. Transprosthetic regurgitation is rare in mechanical prostheses, but is occasionally seen when an occluder is held open by thrombus or vegetations. Because it is far more easily detected transoesophageally such a study is essential when transprosthetic regurgitation is suspected.

On colour flow mapping paraprosthetic regurgitation appears as a region of flow convergence above the sewing ring, a region of flow around the sewing ring, and a jet within the left atrium (fig 3B). Flow convergence appears in the left ventricle and when the transthoracic approach is used it is not significantly obscured by shielding. For this reason it can be imaged in most cases, even when the interatrial jet is eccentric. ${ }^{52}$ With careful angulation of the probe most of the peripheral parts of the left atrium can be imaged particularly in patients with large left atria or with biological valves. Significant jets usually extend well beyond the region of flow shielding and tend to be attracted towards the walls of the left atrium by the forces responsible for flow recruitment. ${ }^{53}$

The jet can usually be localised fairly precisely in the parasternal short axis view. Some jets may be missed ${ }^{54}$ so it is vital that transoesophageal echocardiography is performed if clinical doubt remains after a normal transthoracic study.

It is important to be aware how large normal transprosthetic jets can appear on transoesophageal images. Significant paraprosthetic jets are usually distinguished from normal jets because they are broader, longer, contain more colour aliasing, and have their origin outside the sewing ring (fig 3). They may also be longer in duration, but not invariably. Small paraprosthetic jets are frequently seen on biplane or multiplane imaging and these can only be distinguished reliably from a transprosthetic jet by their base being outside the sewing ring.

Because paraprosthetic jets are common they cannot automatically be assumed to be the cause of symptoms unless they are severe. Unfortunately, it is difficult to quantify regurgitation. The extent of the dehiscence on transthoracic colour flow mapping gives an approximate assessment and this can be supplemented, as in native mitral regurgitation, by examining the density of the jet on-continuous wave Doppler. Because of flow shielding the area of the jet within the left atrium is a poor guide to severity. On transoesophageal echocardiography a jet that is broader than $1 \mathrm{~cm}$ at its base and extends to the back of the left atrium suggests severe regurgitation. Reduced forward flow in the pulmonary veins or flow reversal during systole is further evidence of severe regurgitation. There are also indirect clues from the degree of volume loading of the left ventricle or the pulmonary artery systolic pressure or the clinical examination.

\section{TRICUSPID VALVE}

Obstruction

As with the mitral valve, reduced movement of the cusp or occluder and a narrow colour map in diastole suggest obstruction; but these are difficult to demonstrate. Indirect signs may often be more helpful. A dilated right atrium and failure of the inferior vena cava to collapse in inspiration are non-specific signs of a high right atrial pressure, but when the right ventricle is small they suggest obstruction.

The pressure half time may be difficult to measure because it varies greatly with the respiratory cycle. However, a peak transtricuspid velocity $>1.5 \mathrm{~m} / \mathrm{s}$ in the absence of severe regurgitation suggests obstruction.

\section{Regurgitation}

Because the jet area is directly related to driving pressure its estimation must take account of the fact that pressures are usually lower on the right than on the left. Significant tricuspid regurgitation reduces systolic forward flow in the superior vena cava or hepatic vein, and with severe regurgitation systolic flow may be reversed. The inferior vena cava becomes engorged (diameter $>2.0 \mathrm{~cm}$ ) and it contracts by $<50 \%$ during inspiration. If there is torrential tricuspid regurgitation, the inferior vena cava expands only in systole and not in relation to the respiratory cycle.

\section{PULMONARY VALVE/CONDUIT}

\section{Obstruction}

Though it may be possible to show thickened and immobile cuspal echoes, these are frequently obscured by the sewing ring. A peak velocity of $>3.0 \mathrm{~m} / \mathrm{s}$ on continuous wave Doppler suggests the presence of obstruction. There may be right ventricular hypertrophy. Indirect signs of high right-sided pressures, such as engorgement of the inferior vena cava and reduced systolic flow in the superior vena cava or hepatic veins, are also helpful, particularly for assessing a valved conduit.

\section{Regurgitation}

Regurgitation is easily detected by colour mapping. Its severity is directly related to the width of the colour jet. The density and deceleration slope of the continuous wave signal and the degree of right ventricular diastolic dilatation also give an indication of its severity. 
1 Taylor KM, Gray S-A, Livingstone S, Brannan JJ. The United Kingdom Heart Valve Registry. $\mathcal{F}$ Heart Valve Dis 1992;1:152-9.

2 Burggraf GW, Craige E. Echocardiographic studies of left ventricular wall motion and dimensions after valvular heart surgery. $A m \mathcal{F}$ Cardiol 1975;35:473-80.

3 Gallo I, Ruiz B, Nistal F, Duran CMG. Degeneration in porcine bioprosthetic cardiac valves: incidence of primary tissue failures among 938 bioprostheses at risk. $\mathrm{Am}$ $\mathcal{f}$ Cardiol 1984;53:1061-5.

4 Jamieson WRE, Gallucci V, Thiene G, Bortolotti U, Janusz MT, Milano A, Miyagishima RT. Porcine Valves. I Bodnar E, Frater RWM (eds). Replacement Cardiac I Bodnar E, Frater RWM (eds). Replacement C
valves. 1991 New York: Pergamon, 1991;229-75.

5 Antunes MJ. Bioprosthetic valve replacement in chilAntunes MJ. Bioprosthetic valve replacement in chil-
dren-Long-term follow-up of 135 isolated mitral valve dren-Long-term follow-up of 135 isolated

6 Magilligan DJ, Lewis JW, Tilley B, Peterson E. The porcine bioprosthetic valve 12 years later. $f$ Thorac Cardiovasc Surg 1985;89:499-507.

7 Moront MG, Katz NM. Early degeneration of a porcine aortic valve bioprothesis in the mitral position in an elderly woman and its association with long-term calcium carbonate therapy. Am $\mathcal{F}$ Cardiol 1987;59:1006-7.

8 Jaffe WM, Coverdale HA, Roche AHG, et al. Doppler echocardiography in the assessment of the homograft aortic valve. Am $\mathcal{F}$ Cardiol 1989;63:1466-70.

9 Alam M, Lakier JB, Pickard SD, Goldstein S. Echocardiographic evaluation of porcine bioprosthetic valves: experience with 309 normal and 59 dysfunctioning valves. Am $\mathcal{F}$ Cardiol 1983;52:309-15.

10 Kupari M, Tötterman KJ, Ventilä M, Harjula A, Mattila S. Auscultatory and echophonocardiographic characterS. Auscultatory and echophonocardiographic characteristics of the normally-functioning Medtronic-
valve prosthesis. Eur Heart $\mathcal{F} 1985 ; 6: 779-85$.

11 Amann FW, Burckhardt D, Hasse J, Grädel E. Echocardiographic features of the correctly functioning $\mathrm{S}$ Jude Medical valve prosthesis. Am Heart $\mathcal{f} 1981$; 101:45-51.

12 Chambers JB, Monaghan MJ, Jackson G. Colour flow Doppler mapping in the detection and localisation of prosthetic valve regurgitation. Br Heart f 1989;62:1-8.

13 Gibbs JL, Wharton GA, Williams GJ. Doppler echocardiographic characteristics of the Carpentier-Edwards xenograft. Eur Heart $\mathcal{F}$ 1986; 7:353-6.

14 Mohr-Kahaly S, Kupferwasser I, Erbel R, Delert H, Meyer $\mathrm{J}$. Regurgitant flow in apparently normal valve prostheses: improved detection and semiquantitative analysis by transesophageal two-dimensional color-coded Doppler transesophageal two-dimensional color-coded D

15 Chambers J, Cross J, Deverall P, Sowton E. Echocardiographic description of the CarboMedics bileaflet prosthetic heart valve. $₹$ Am Coll Cardiol 1993;21:398-405.

16 Alam M, Serwin JB, Rosma HS, Polanco GA, Sun I, Silverman NA. Transesophageal echocardiographic features of normal and dysfunctioning bioprosthetic valves Am Heart $\mathcal{F}$ 1991;121:1149-55.

17 Cooper DM, Stewart WJ, Schiavone WA, Lombardo HP, Lytle BW, Loop FD, Salcedo EE. Evaluation of normal prosthetic valve function by Doppler echocardiography. Am Heart f 1987;114:576-82.

18 Panidis IP, Ross J, Mintz GS. Normal and abnormal proshetic valve function as assessed by Doppler echocardiography. $₹$ Am Coll Cardiol 1986;8:317-26.

19 Ramirez ML, Wong M, Sadler N, Shah PM. Doppler evaluation of bioprosthetic and mechanical aortic valves: Data from four models in 107 stable ambulatory patients. Am Heart $\mathcal{f} 1988 ; 115: 418-25$.

20 Nihoyannopoulos P, Kambouroglou D, Athanassopoulos G, Nadazdin A, Smith P, Oakley CM. Doppler haemodynamic profiles of clinically and echocardiographically normal mitral and aortic valve prostheses. Eur Heart $f$ normal mitral and

21 Williams GA, Labovitz AJ. Doppler hemodynamic evaluation of prosthetic (Starr-Edwards and Björk-Shiley) and bioprosthetic (Hancock and Carpentier-Edwards) cardiac valves. Am $千$ Cardiol 1985;56:325-32.

22 Gibbs JL, Wharton GA, Williams GJ. Doppler ultrasound of normally functioning mechanical mitral and aortic valve prostheses. Int $\mathcal{F}$ Cardiol 1988;18:391-8.

23 Chafizadeh ER, Zoghbi WA. Doppler echocardiographic assessment of the St Jude Medical prosthetic valve in the aortic position using the continuity equation. Circulation 1991;83:213-23.

24 Rijsterborgh H, Roelendt J. Doppler assessment of aortic stenosis: Bernouilli revisited. Ultrasound Med Biol 1987;13:241-8.

25 Chambers J, Deverall P. Limitations and pitfalls in the assessment of prosthetic valves using Doppler ultraassessment of prosthetic valves using Doppler ul
sound. $\mathcal{F}$ Thorac Cardiovasc Surg 1992;104:495-501.

26 Ihlen H, Molstad P, Simonsen S, et al. Hemodynamic evaluation of the CarboMedics prosthetic heart valve in the aortic position: comparison of noninvasive and invasive techniques. Am Heart $\mathcal{F}$ 1992;123:151-9.

27 Chambers J, Spiropoulos G. The continuity equation: a comparison of the classical and modified forms. $A m \mathcal{F}$ Noninvasive Invest (in press)

28 Skjaerpe T, Hegrenaes L, Hatle L. Non-invasive estimation of valve area in patients with aortic stenosis by Doppler ultrasound and two dimensional echocardiography. Circulation 1985;72:810-8.

29 Chambers J, Coppack F, Deverall P, Jackson G, Sowton E. The continuity equation tested in a bileaflet aortic prosthesis. Int $\mathcal{f}$ Cardiol 1991;31:149-54.
30 Stoddard MF, Dawkins PR, Longaker RA. Mobile strands are frequently attached to the St Jude Medical mitra valve prosthesis as assessed by two-dimensional transesophageal echocardiography. Am Heart $f$ 1992;124 $671-4$.

31 Iung B, Cormier B, Dadez E, et al. Small abnormal echo after mitral valve replacement with bileaflet mechanical prostheses: predisposing factors and effect on thrombrostheses: predisposing factors and effect on

32 Jones M, Eidbo EE. Doppler color flow evaluation of prosthetic mitral valves: experimental epicardial studies. $\mathcal{F}$ Am Coll Cardiol 1989;13:234-40.

33 Taams MA, Gussenhoven EJ, Cahalan MK, et al. Transesophageal Doppler color flow imaging in the Transesophageal Doppler color flow imaging in the detection of native and Björk-Shiley mi

34 van den Brink RBA, Visser CA, Basart DCG, Düren DR de Jong AP, Dunning AJ. Comparison of transesophageal and transthoracic color Doppler flow imaging in patients with mechanical prostheses in the mitral valve position. Am $\mathcal{F}$ Cardiol 1989;63:1471-4.

35 Mohr-Kahaly S, Kupferwasser I, Erbel R, Toot M, Oeler $\mathrm{H}$, Meyer J. Transesophageal evaluation of aortic valve prostheses. In: Erbel R, Khanderia BK, Brennecke R, Meyer J, Seward JB, Tajik AJ, eds. Transesophageal echocardiography: A new window on the heart. Berlin Springer-Verlag, 1989:183-90.

36 Kyo S, Takamoto S, Matsumara M, et al. Immediate and early postoperative evaluation of results of cardiac surgery by transesophageal two-dimensional Doppler echocardiography. Circulation 1987;76(suppl V):113-21.

37 Schartl M, Dreysse S, Weimann E, et al. Evaluation of mitral valve prostheses by transesophageal echocardiography. In: Erbel R, Khanderia BK, Brennecke R, Meyer J,
Seward JB, Tajik AJ, eds. Transesophageal echocardiography: A new window on the heart. Berlin: SpringerVerlag, 1989:183-90.

38 Hatle L, Angelsen B, Tromsdal A. Noninvasive assessment of atrioventricular pressure half-time by Doppler ultrasound. Circulation 1989;60:1096-1104.

39 Thomas JD, Weyman AE. Doppler mitral pressure halftime: A clinical tool in search of theoretical justification. $f$ Am Coll Cardiol 1987;10923-9.

40 Schiller NB. Pulmonary artery pressure estimation by Doppler and two-dimensional echocardiography. Cardiol Clin 1990;8:277-87.

41 Aoyagi S, Nishi Y, Kawara T, Oryoji A, Kosuga K, Ohishi $\mathrm{K}$. Doppler echocardiographic evaluation of St Jude Medical valves in the tricuspid position. $f$ Heart Valve Dis 1993;2:279-86.

42 Pye M, Weerasana N, Bain WH, Hutton I, Cobbe SM Doppler echocardiographic characteristics of normal and dysfunctioning prosthetic valves in the tricuspid and mitral position. Br Heart f 1990;63:41-4.

43 Cunha CLP, Giuliani ER, Callahan JA, Pluth JR. Echophonocardiographic findings in patients with prosthetic heart valve malfunction. Mayo Clin Proc 1980;55:231-42.

44 Alam M, Goldstein S, Lakier JB. Echocardiographic changes in the thickness of porcine valves with time. Chest 1981;79:663-8.

45 Chandraratna PA, Nanna M, McKay C, Nimalasuriya A, Swinney R, Elkayam U, Rahimtoola SH. Determination of cardiac output by transcutaneous continuous-wave ultrasonic Doppler computer. Am $\mathcal{F}$ Cardiol 1984;53: 234-7.

46 Kapur KK, Fan P, Nanda NC, Yoganathan AP, Goyal RG. Doppler color flow mapping in the evaluation of prosthetic mitral and aortic valve function. $¥ \mathrm{Am} \mathrm{Coll}$ prosthetic mitral and aortic
Cardiol 1989;13:1561-71.

47 Chambers JB. The haemodynamic assessment of prosthetic valves using Doppler ultrasound. In: Chambers JB, Monaghan MJ, eds. Echocardiography: an international review. Oxford: Oxford University Press, 1993

48 Isihara O, Ferrans VJ, Boyce SW. Structure and classification of cuspal tears and perforations in porcine bioprosthetic cardiac valves implanted in patients. $A m \mathcal{F}$ Cardiol 1981;48:665-8.

49 Forman MB, Phelan BK, Robertson RM, Virmani R Correlation of two-dimensional echocardiography and pathologic findings in porcine valve dysfunction. $7 \mathrm{Am}$ Coll Cardiol 1985;5:224-30.

50 Effron MK, Popp RL. Two-dimensional echocardiographic assessment of bioprosthetic valve dysfunction and inefective

51 Dittrich H, Nicod P, Hoit B, Dalton N, Sahn D. Evaluation of Björk-Shiley prosthetic valves by real-time two-dimensional Doppler echocardiographic flow mapping. Am Heart $\mathcal{f}$ 1988;115:133-8.

52 Bargiggia GS, Tronconi L, Raisaro A, et al. Color Dopple diagnosis of mechanical prosthetic mitral regurgitation diagnosis of mechanical prosthetic mitral regurgitation:
usefulness of the flow convergence region proximal to usefulness of the flow convergence region proximal to

53 Cape EG, Yoganathan AP, Weyman AE, Levine RA. Adjacent solid boundaries alter the size of regurgitan jets on Doppler color flow maps. $7 \mathrm{Am}$ Coll Cardio 1991;17:1094-102.

54 Nellessen U, Schnittger J, Appleton CP, et al. Transesophageal two dimensional echocardiography and color Doppler flow velocity mapping in the evaluation of cardiac valve prostheses. Circulation 1988;78: 848-55.

55 Weinstein IR, Marbarger JP, Perez JE. Ultrasonic assess- 
ment of the St Jude prosthetic valve: $M$ mode, twodimensional, and Doppler echocardiography. Circulation 1983;68:897-905.

56 Habib G, Benichou M, Bonnet J-L et al. Assessment of normal and abnormal prosthetic mitral valves by normal and abnormal prosthetic mitral valves by Doppler echocardio

57 Chambers J, Deverall P, Jackson G, Sowton E. The Hatle orifice area formula tested in normal bileaflet mechanical mitral prosthesis. Int $\mathcal{F}$ Cardiol 1992;35:397-404.

58 Chambers JB. Studies on the use of Doppler ultrasound in the assessment of prosthetic cardiac valve function. Cambridge: Cambridge University, 1990. MD thesis. pp 301.

59 Gibbs JL, Wharton GA, Williams GJ. Doppler ultrasound of normally functioning mechanical mitral and aortic valve prostheses. Int 7 Cardiol 1988;18:91-8

60 Simpson IA, Reece IJ, Houston AB, Hutton I, Wheatley DJ, Cobbe SM. Non-invasive assessment by Doppler DJ, Cobbe SM. Non-invasive assessment by Doppler
ultrasound of 155 patients with bioprosthetic valves: a comparison of the Wessex porcine, low profile Ionescucomparison of the Wessex porcine, low profile Ionescu-
Shiley, and Hancock pericardial bioprostheses. Br Heart $\mathcal{F}$ Shiley, and Hanc

61 Ryan T, Armstrong WF, Dillon JC, Feigenbaum H. Doppler echocardiographic evaluation of patients with porcine mitral valves. Am Heart $\mathcal{F}$ 1986;111:237-44.

62 Dumesnil JG, Honos GN, Lemieux M, Beauchemin J. Validation and applications of indexed aortic prosthetic valve area calculated by Doppler echocardiography. 7 Am Coll Cardiol 1990;16:637-43.

\section{British Society of Echocardiography Scientific Session and Annual General Meeting at the British Cardiac Society Meeting, Torquay Thursday 19 May 1994}

07.45 Coffee and registration

08.00-09.30 Scientific Session: Controversies in echocardiography

08.00-08.45 Colour Doppler is of no value in adult cardiac diagnosis

Protagonist: Graham Leech

Antagonist: John Chambers

Chairman: $\quad$ Alan Houston

08.45-09.30 Transoesophageal echo should only be performed in a tertiary cardiac centre

Protagonist: Iain Simpson

Antagonist: Stephen Saltissi

Chairman: Roger Hall

The format for the session on controversies in echocardiography will be an audience vote on the proposal, 15 minutes each for the protagonist and antagonist, 15 minutes of questions from the audience directed by and supported by the (impartial) chairman, and finally another audience (hands-up) vote.

\subsection{0-10.30 BSE Annual General Meeting}

President: Mark J Monaghan

Secretary: Caroline Westgate

Treasurer: Edward Southall 